\title{
PENGARUH WAKTU FERMENTASI TERHADAP KARAKTERISTIK KIMIA DAN ORGANOLEPTIK TAPE PISANG KEPOK
}

\author{
Effect of Fermentation Time on Chemical Characteristic and Organoleptic of \\ Kepok Banana Tape \\ Cahyaning Rini Utami \\ Prodi Ilmu dan Teknologi Pangan, Fakultas Pertanian, Universitas Yudharta Pasuruan \\ Email : cahyaningriniutami@gmail.com
}

\begin{abstract}
Tape is one of traditional Indonesian fermented food. Kepok banana can be used as tape because of having resistence starch and high fiber food. Starch content at kepok banana is 22$25 \%$. The quality of banana tape is determined based on chemical characterization during fermentation process. In fermentation of tape have three compound as the products are sugar, alcohol, and organic acid so in this study chemical characteristic that measured are pH, sugar content, and alcohol content as quality control. This research was aimed to know the effect of fermentation time on the chemical characteristic and organoleptic of kepok banana tape. The study was being conducted making kepok banana tape with various fermentation time of 1, 2, 3, 4, 5 and 6 days. The results of fermentation was analyzed by $\mathrm{pH}$, sugar content, alcohol content, and organoleptic. All of data was analyzed by one way ANOVA and continued by BNT test. The result show that fermentation time have effect to chemical characteristic and organoleptic. The best kepok banana tape was produced on third days with chemical characteristic: pH 4,76; sugar content 11,97\%; alcohol content 4,45\% and organoleptic value to taste, color, texture, and flavor were 5.34; 5.56 ; 4.43; and 5.26 respectively (4=least liked, 5=liked). Based on chemical characteristic and organoleptic test, kepok banana tape good for consumption with fermentation time 3-4 days.
\end{abstract}

Keywords: Tape, Kepok banana, Fermentation time, Chemical characteristic

\begin{abstract}
ABSTRAK
Tape merupakan salah satu makanan fermentasi tradisional di Indonesia. Pisang kepok dapat dimanfaatkan sebagai bahan dasar membuat tape karena memiliki kelebihan pati yang resisten dan serat tinggi. Kandungan pati yang ada pada pisang kepok sekitar 22-25\%. Kualitas tape pisang ditentukan berdasarkan karakteristik kimia selama proses fermentasi. Dalam fermentasi tape sendiri selalu melibatkan tiga senyawa sebagai produknya yakni gula, alkohol, dan asam organik sehingga karakteristik kimia yang diukur sebagai kontrol kualitas adalah $\mathrm{pH}$, kadar gula dan kadar alkohol. Penelitian ini bertujuan untuk mengetahui pengaruh waktu fermentasi tape pisang kepok terhadap karakteristik kimia dan organoleptik. Penelitian ini dilakukan dengan membuat tape pisang kepok dengan variasi waktu fermentasi selama 1, 2, 3, 4, 5 dan 6 hari. Hasil fermentasi diuji pH, kadar gula, kadar alkohol dan organoleptik. Seluruh data dianalisa menggunakan analisis varian (ANOVA) satu arah yang dilanjutkan dengan uji BNT. Hasil penelitian menunjukkan waktu fermentasi berpengaruh terhadap karakteristik kimia dan organoleptik. Tape pisang kepok terbaik dihasilkan pada hari ketiga dengan karakteristik kimia: pH 4,76; kadar gula 11,97\%; kadar alkohol 4,45\% dan nilai organoleptik terhadap rasa, warna, tekstur, dan aroma berturut-turut sebesar 5,34; 5,56; 4,43; dan 5,26 (4= sedikit suka, 5= suka). Berdasarkan hasil uji karakteristik kimia dan organoleptik tape pisang kepok dengan waktu fermentasi 3- 4 hari layak untuk dikonsumsi.
\end{abstract}

Kata kunci: Tape, Pisang kepok, Waktu Fermentasi, Karakteristik kimia 


\section{PENDAHULUAN}

Makanan fermentasi adalah makanan yang digunakan sebagai menu makanan sehari hari karena cara membuatnya sangat mudah, praktis, dan aman. Banyak keuntungan yang dapat diambil dari makanan hasil fermentasi diantaranya baik untuk kesehatan tubuh, memiliki cita rasa yang khas, dan memiliki nilai gizi yang lebih baik. Oleh karenanya, makanan fermentasi menjadi lebih penting untuk menjaga kesehatan tubuh (Fanworth, 2003). Salah satu makanan fermentasi yang disukai adalah tape.

Tape merupakan makanan hasil fermentasi yang sangat populer di Indonesia. Bahan yang biasanya digunakan untuk membuat tape adalah bahan yang mengandung pati seperti singkong (Manihot utilissima Pohl) yang telah dilakukan oleh (Hasanah, 2012). Zat pati yang ada dalam bahan makanan diubah menjadi bentuk yang sederhana yaitu gula, dengan bantuan suatu mikroorganisme yang disebut ragi atau khamir.

Salah satu alternatif bahan berpati untuk membuat tape adalah buah pisang mengingat produksi buah pisang menduduki peringkat pertama hasil pertanian di Indonesia. Pemanfaatan buah pisang sendiri baik dari kulit sampai buahnya sudah banyak dilakukan. Dari segi energi, limbah pisang dapat dimanfaatkan sebagai bahan baku pembuatan bioetanol (Suryaningsih dan Pasaribu, 2015). Dari segi pangan, pisang dimanfaatkan untuk tepung, wine, dan pembuatan asam cuka (ByarugabaBazirake G.W., 2014) Pembuatan tape pisang sendiri merupakan alternatif baru penganekaragaman olahan buah pisang dibidang pangan.

Pisang yang dipilih sebagai bahan dasar tape adalah jenis pisang kepok (Musa paradisiaca $L$ ). Pisang kepok ini memiliki kelebihan kandungan pati yang resisten dan serat yang tinggi. Kandungan pati dalam pisang kepok sebesar 22-25\%. Pisang kepok mengandung senyawa fruktooligosakarida sekitar $0,3 \%$ yang merupakan sumber prebiotik (Umam, M. F. 2012). Pisang kepok termasuk pisang berkulit tebal dengan kulit berwarna kuning apabila sudah matang. Tingkat kematangan pisang menjadi pertimbangan dalam hal membuat pisang. Perubahan kimia yang sangat menonjol pada saat proses pematangan pisang secara alamiah adalah perubahan pati menjadi gula. Saat buah pisang sudah matang, sebagian besar pati akan berubah menjadi sukrosa, glukosa dan fruktosa serta sejumlah kecil maltosa. Kadar pati serentak turun dari $20 \%$ daging buah menjadi $1-2 \%$ (Shiga, Carpita, Lajolo, CordenunsiLysenko, 2017). Kandungan gula pada pisang yang matang akan lebih dominan sehingga mempengaruhi senyawa yang terbentuk pada saat proses peragian (fermentasi). Proses fermentasi bahan yang mengandung gula oleh yeast akan menghasilkan etanol sebagai produk akhirnya. Pada penelitian ini pisang yang akan diolah adalah pisang kepok yang agak matang, dengan harapan agar tape yang dihasilkan memiliki rasa dominan tape daripada rasa asam atau alkohol.

Kualitas tape secara umum ditentukan dari segi rasa. Tape memiliki rasa manis, sedikit asam dan beraroma alkohol. Fermentasi tape terjadi karena adanya aktivitas mikroba yang mengubah pati menjadi gula, sebagian gula akan diubah menjadi alkohol dan komponen flavor. Selain dari segi rasa, kualitas tape juga dapat ditentukan dari karakteristik kimia tape. Karakteristik dari tape yang bisa diukur adalah jumlah gula, jumlah alkohol dan $\mathrm{pH}$ (derajat keasaman).

Beberapa penelitian yang telah dilakukan adalah menguji karakteristik kimia tape berbahan dasar selain pisang dengan satu parameter saja. Yulianti (2014) telah melakukan uji kadar alkohol pada tape beras, ketan, dan singkong dengan variasi waktu fermentasi. Santosa (2010) melakukan kajian tentang tape buah sukun dengan uji $\mathrm{pH}$, tekstur, rasa sebagai parameter kualitas tape. Dalam fermentasi tape sendiri selalu melibatkan tiga senyawa sebagai produknya yakni gula, alkohol, dan 
asam organik sehingga perlu dikaji parameter $\mathrm{pH}$, kandungan gula, dan alkohol sekaligus untuk menentukan kualitas dari tape pisang pada penelitian ini. Pembuatan tape dari pisang sudah dilakukan tetapi untuk jenis pisang yang bebeda. Unika dan Astuti (2015) membuat tape berbahan dasar pisang tanduk dengan variasi waktu dan dosis ragi. Penelitian mengenai tape berbahan dasar pisang kepok masih jarang dilakukan.

Faktor yang mempengaruhi fermentasi salah satunya adalah waktu fermentasi. Waktu fermentasi akan mempengaruhi kualitas tape dalam hal layak tidaknya dikonsumsi. Berdasarkan hal tersebut maka perlu dikaji tentang pengaruh waktu fermentasi terhadap kualitas tape jenis pisang kepok. Kualitas tape pisang kepok dengan variasi lama fermentasi diuji melalui karakteristik kimianya $(\mathrm{pH}$, jumlah gula, jumlah alkohol) dan didukung dengan uji organoleptik untuk melihat tingkat kesukaan orang mengkonsumsi tape pisang.

\section{METODE PELAKSANAAN}

\section{Alat dan Bahan}

Bahan yang digunakan dalam penelitian ini: pisang kepok dengan tingkat kematangan yang seragam, dipilih sedikit matang, ragi tape merk NKL yang sudah dihaluskan, akuades.

Peralatan yang digunakan dalam penelitian:(1) Peralatan untuk preparasi berupa piring, garpu, pisau, baskom, sarung tangan, timbangan analitikal Mettler Toledo MS204S, (2) Peralatan untuk pengolahan berupa kompor, dandang, daun pisang, termometer suhu ruang, plastik (3) Peralatan untuk pengujian berupa: pHmeter digital TOA DKK HM-3OP, tabung reaksi, gelas ukur 5, 10, $20 \mathrm{~mL}, 1$ set destilasi fraksional, pemanas listrik densitymeter Mettler Toledo DM40, mortar, magnetic stirer Labinco, kertas saring Whatman no.92, piknometer HITACHI skala 0-100.

\section{Pelaksanaan Penelitian}

\section{Pembuatan Tape Pisang Kepok}

Sebanyak $500 \mathrm{~g}$ pisang kepok disortasi, dikupas kulitnya dan dicuci air bersih. Pisang yang sudah bersih dikukus selama 15-20 menit. Pada saat dikukus dijaga tingkat kematangannya agar tidak matang sempurna dengan ditandai perubahan warna daging buah kuning muda dengan tekstur lunak. Pisang diangkat dan dibiarkan dingin selama 1 jam.

Sebanyak $100 \mathrm{~g}$ pisang yang sudah dikukus ditimbang dan ditambahkan ragi tape sebesar $0,5 \%$ (b/b) secara merata kesemua bagian. Pemberian inokulum ragi tape tersebut didasarkan pada literatur bahwa inokulum yang ditambahkan dalam pembuatan tape biasanya kurang dari $1 \%$ per kilogam bahan, dan umumnya 0,2-0,5\% dengan suhu fermentasi pada suhu ruang antara 25-30 ${ }^{\circ} \mathrm{C}$ (Hidayat, 2006). Pisang yang sudah diberi ragi tersebut dibungkus dengan daun pisang dan disimpan dengan variasi waktu fermentasi 1, 2, 3, 4, 5 dan 6 hari pada suhu ruang. Perlakuan masingmasing sampel diulang sampai dua kali (duplo) pengulangan sehingga terdapat 12 kali percobaan. Sampel hasil fermentasi diuji $\mathrm{pH}$ menggunakan $\mathrm{pHmeter}$.

\section{Penentuan Kadar Gula}

Kadar gula ditentukan menggunakan metode Brix (Gebregergs et al., 2016). Tape hasil fermentasi dihaluskan menggunakan mortar. Sebanyak 5 gram sampel ditimbang dan diencerkan ke dalam labu ukur $100 \mathrm{~mL}$. Larutan sampel dihomogenkan dengan pengaduk magnetik selama 10 menit. Larutan sampel yang homogen disaring dan dianalisa dengan densitymeter untuk menentukan brix. Hasil dibaca pada layar monitor. Cara perhitungan (\% brix):

Brix $(\%)=$ hasil brix $\mathrm{x}$ faktor pengenceran.

\section{Penentuan Kadar Alkohol}

Kadar alkohol ditentukan dengan destilasi sampel terlebih dahulu kemudian diukur dengan alat piknometer (Sugiyono, 2010). Tape pisang hasil fermentasi yang sudah dilarutkan dengan air didestilasi 
dengan suhu terkontrol $75-78{ }^{\circ} \mathrm{C}$ (titik didih etanol) sampai tidak ada yang keluar sebagai destilat. Destilat yang diperoleh merupakan alkohol, kemudian ditentukan volume dan kadar alkoholnya dengan alkoholmeter.

Kadar alkohol (\%) :

Fp x Pembacaan skala alkoholmeter (\%).

\section{Uji Organoleptik}

Pengujian organoleptik tape pisang kepok dengan variasi waktu fermentasi dilakukan oleh 15 panelis dari berbagai tingkat usia, pendidikan dan pekerjaan. Rentang skor 1-7 (sangat suka sampai tidak suka). Parameter yang diuji meliputi, warna, rasa, tekstur dan aroma.

\section{Analisis Statistik}

Data yang diperoleh dianalisis statistik menggunakan ANOVA satu arah (one way) selang kepercayaan 5\%, dilanjutkan dengan uji BNT untuk melihat tingkat signifikan antar perlakuan.

\section{HASIL DAN PEMBAHASAN}

\section{Karakteristik Kimia Tape Pisang pH}

Berdasarkan hasil uji nilai $\mathrm{pH}$ rata-rata dari tape pisang kepok berkisar antara 4,924,61 selama proses fermentasi dapat dilihat pada Gambar 1. Menurut mikroorganisme pada fermentasi tape termasuk dalam mikroorganisme asidofilik yaitu mikroorganisme yang mampu hidup pada kisaran pH antara 2 sampai 5 (Bede et al., 2015). Analisis ragam menunjukkan bahwa perlakuan waktu fermentasi berpengaruh nyata terhadap nilai $\mathrm{pH}$ dari tape pisang kepok antara waktu fermentasi hari pertama sampai dengan hari kelima. Terjadi penurunan $\mathrm{pH}$ tape pisang seiring lamanya waktu fermentasi. Penurunan $\mathrm{pH}$ disebabkan oleh aktivitas mikroba yang merombak pati dari pisang menjadi senyawa dengan produk alkohol. Alkohol merupakan senyawa yang bersifat asam. Semakin lama waktu fermentasi alkohol semakin banyak terbentuk, $\mathrm{pH}$ semakin turun.

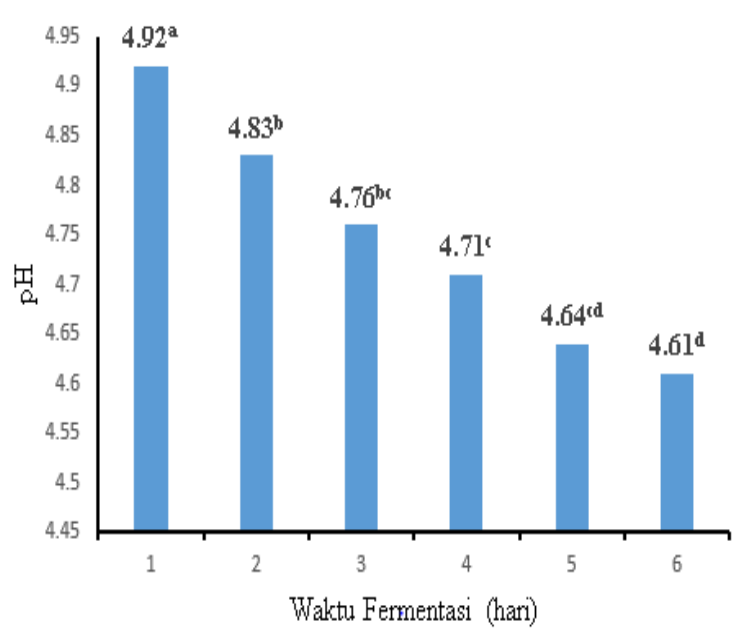

Gambar 1. Nilai rata-rata $\mathrm{pH}$ Tape pisang Kepok dengan variasi Waktu Fermentasi.

Berdasarkan Gambar 1 nilai $\mathrm{pH}$ paling kecil terjadi pada fermentasi hari ke-6 dengan nilai sebesar 4,61 dan diperkirakan akan turun terus jika fermentasi dilanjutkan. Apabila proses fermentasi tape terus berlanjut maka terbentuk asam-asam organik karena adanya mikroba dalam ragi tape. Didalam ragi tape terdapat berbagai spesies yang memiliki kemampuan yang berbeda-beda dalam fermentasi menghasilkan tape. Dalam ragi tape mikroba Aspergillus dapat merombak pati menjadi glukosa. Saccharomyces, Candida dan Hansenula mengkonversi glukosa menjadi alkohol, sedangkan Acetobacter dapat merombak alkohol menjadi asam (Dwijoseputro, 2005).

\section{Kadar Gula Reduksi}

Gula merupakan faktor utama dalam fermentasi tape karena tape yang baik memiliki rasa dominan manis. Pada penelitian ini, gula yang ditentukan adalah gula reduksi. Hasil uji kadar gula reduksi rata-rata memiliki rentang 14,34-9,16\% selama fermentasi ditunjukkan pada Gambar 2. Berdasarkan analisis ragam menunjukkan bahwa perlakuan waktu fermentasi berpengaruh nyata terhadap kadar gula dari tape pisang kepok. Kadar gula reduksi tertinggi terjadi pada hari pertama fermentasi sebesar $14,34 \%$. Kadar gula yang tinggi pada hari pertama fermentasi 
disebabkan: pertama, pada penelitian ini menggunakan pisang sedikit matang sehingga pisang sebelum fermentasi sudah mengandung gula. Kedua, sebagian pati yang terkandung dalam pisang mengalami pemecahan menjadi gula saat proses pengukusan. Pisang dengan jenis pisang kepok memiliki kandungan gula sebesar $12,23 \mathrm{~g}$, pati sebesar 22,84 g per 100 gram sehingga menyebabkan buah pisang matang memiliki rasa manis (Aurore et al., 2009).

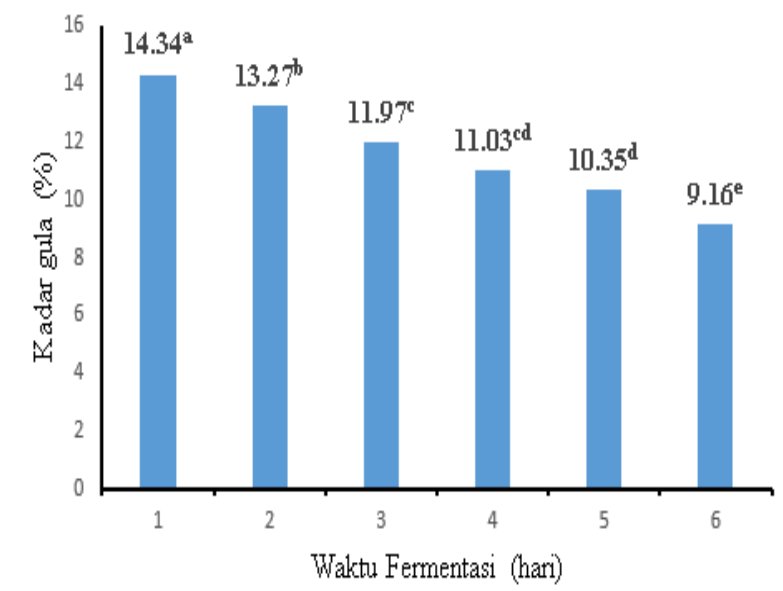

Gambar 2. Nilai Rata-rata Kadar Gula Tape Pisang Kepok dengan Variasi Waktu Fermentasi

Gambar 2 menunjukkan kadar gula semakin menurun seiring lamanya waktu fermentasi. Penurunan kadar gula signifikan terlihat pada fermentasi hari ke-6 dan diperkirakan akan turun terus jika waktu fermentasi berlanjut. Hal tersebut karena perubahan glukosa menjadi etanol oleh kerja yeast yang ada dalam ragi tape. Paulinea et al. 2017 telah menunjukkan penurunan gula hasil fermentasi pisang menggunakan yeast untuk produksi minuman alkohol. Kadar gula terendah sebesar $9,16 \%$ dengan waktu fermentasi 6 hari. Pada hari ketiga sampai kelima kadar gula masih cukup tinggi dengan rentang rata-rata 11,97-10,35\% karena adanya aktivitas Aspergillus dalam ragi tape yang mengubah pati pisang menjadi gula. Proses fermentasi pada tape melibatkan tiga tahap, yaitu (1) pemecahan pati menjadi glukosa oleh Aspergillus sp., (2) Perubahan glukosa menjadi etanol oleh kerja khamir, dan (3) Perubahan etanol menjadi asam asetat oleh Acetobacter, sehingga tape terasa asam (Barus, 2011).

\section{Kadar Alkohol}

Berdasarkan hasil uji alkohol menunjukkan bahwa terjadi kenaikan jumlah alkohol selama proses fermentasi. Analisis ragam menunjukkan bahwa perlakuan waktu fermentasi berpengaruh sangat nyata terhadap kadar alhokol tape pisang kepok. Hasil kadar alkohol rata-rata tape pisang kepok pada hari pertama sampai keenam dapat dilihat pada Gambar 3.

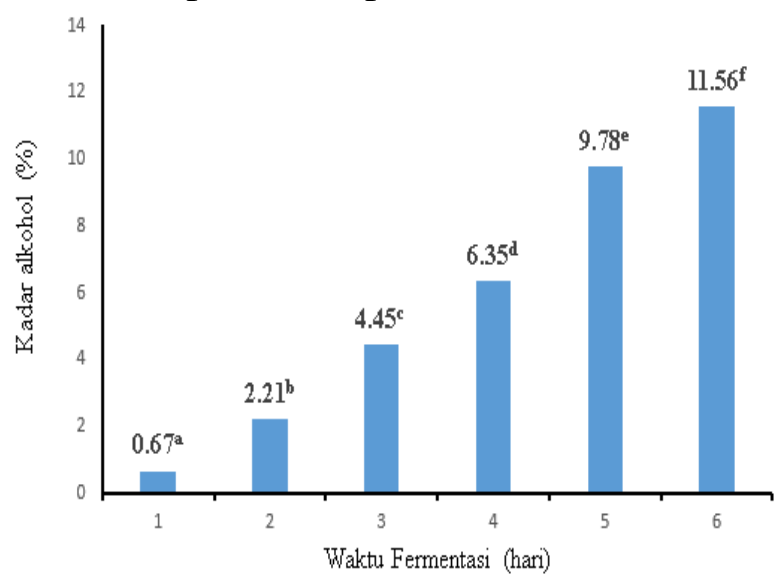

Gambar 3. Nilai Rata-rata Kadar Alkohol Tape Pisang Kepok dengan Variasi Waktu Fermentasi

Kenaikan jumlah alkohol seiring dengan bertambahnya waktu fermentasi karena semakin lama fermentasi maka semakin banyak glukosa yang dirombak menjadi alkohol sehingga kadar alkohol yang dihasilkan semakin tinggi. Pada hari pertama, kadar alcohol masih sangat sedikit yaitu sebesar $0,67 \%$. Hal ini disebabkan bakteri Sacharomyces cerevisiae dalam ragi belum aktif dan masih dalam tahap adaptasi. Meningkatnya kadar alkohol yang dihasilkan oleh tape pisang kepok berkaitan dengan fase-fase pertumbuhan Sacharomyces cereviciae, yang dimulai dari fase adaptasi (Lag phase), fase eksponensial (Log phase), fase stasioner (Stationer phase), dan fase kematian (Death phase) (Paulinea et al., 2017).

Gambar 3 menunjukkan jumlah alkohol tertinggi terjadi pada hari keenam dengan perbedaan yang cukup signifikan 
dengan nilai sebesar 11,56\%. Menurut Alfarenga et al. (2011) menunjukkan bahwa dalam selang waktu 1- 7 hari kadar etanol dalam tape terus meningkat, sedangkan setelah 7 hari kadar etanol dalam tape menurun. Menurut SNI No. 01-4018-1996 mengenai batas kadar alkohol dalam makanan dan minuman adalah sebesar 8$20 \%$, artinya tape pisang kepok pada hari keenam masih dalam batas normal. Dari hasil kesepakatan MUI, makanan dan minuman yang mengandung alkohol tidak boleh melebihi $1 \%$, sehingga makanan dan minuman yang mengandung kadar alkohol melebihi $1 \%$ termasuk dalam kategori haram untuk dikonsumsi (Hasanah, 2012). Namun, batas maksimal yang ditetapkan oleh MUI tersebut berlaku hanya apabila pada kadar alkohol sebesar $1 \%$ dalam suatu makanan dapat menyebabkan konsumen merasa hilang kesadaran atau mabuk.

\section{Organoleptik Tape Pisang Kepok}

Uji Organoleptik dilakukan untuk mengetahui tingkat penerimaan konsumen terhadap tape yang terbuat dari pisang kepok dengan perbedaan waktu fermentasi. Hasil uji organoleptik ditampilkan pada Tabel 1 . Kesukaan panelis terhadap parameter rasa, warna, tekstur dan aroma berturut-turut berkisar pada nilai 1,84 sampai 5,$34 ; 2,10$ sampai 4,$50 ; 2,30$ sampai 5,$56 ; 1,78$ sampai 5,26 (tidak suka sampai suka). Hasil uji lanjut menyatakan skor rasa tertinggi dihasilkan pada tape pisang dengan waktu fermentasi 3 hari yang berbeda tidak nyata dengan waktu fermentasi 4 hari dan berbeda nyata pada waktu fermentasi 1, 2, 5 dan 6 hari. Kesukaan panelis terhadap rasa tersebut disebabkan pada hari ke-3 dan ke-4 menunjukkan khas tape yang ideal. Rasa tape yang ideal artinya komposisi gula masih dominan dengan sedikit asam beralkohol yang sejalan dengan karakteristik kimia sebelumnya. Pada hari pertama tape belum terbentuk sehingga rasa khas dari tape belum muncul, baru muncul pada hari kedua dan meningkat hari berikutnya. Menurut Unika (2015) rasa tape meningkat pada hari kedua ketiga dan keempat, akan menurun pada hari ke-5.

Tabel 1. menunjukkan hasil uji dengan parameter aroma sama dengan hasil uji rasa yaitu skor tertinggi ditunjukkan pada hari ke-3 dan ke-4 sebesar 5,26 dan 5,22. Tingkat kesukaan panelis terhadap aroma menurun setelah hari kelima karena jumlah alkohol pada tape meningkat (lihat Gambar 3) dan keasamannya tinggi (lihat Gambar 1). Menurut Hasanah (2012), semakin lama proses fermentasi, maka kadar alkohol dan keasamannya akan semakin tinggi yang membuat aroma tape semakin menurun.

Hasil uji lanjut menunjukkan perlakuan lama fermentasi hari ketiga dan keempat berbeda tidak nyata terhadap warna tape pisang kepok. Begitu juga dengan hari kelima tidak berbeda nyata dengan hari keenam. Warna tape pisang akan berubah menjadi kuning cerah semakin lama proses fermentasi. Perubahan warna pada tape pisang salah satunya disebabkan oleh adanya saccharomyses cerevisiae, candida, Hansenulla. Saccharomyses cerevisiae merupakan khamir "permukaan" dan selama fermentasi terbawa ke permukaan bahan yang sedang difermentasi oleh gelembunggelembung karbondioksida yang oleh karenanya memproduksi bagian atas yang mengandung khamir (Barus, 2011).

Berdasarkan Tabel 1. tingkat kesukaan panelis terhadap tekstur tape pisang tertinggi pada fermentasi hari ketiga sebesar 5,56 dan paling rendah pada hari pertama sebesar 2,30. Pada hari pertama, tekstur tape masih agak keras sedangkan pada hari keenam teksturnya sangat lunak. Menurut Hidayat dan Suhartini (2009), semakin lama proses fermentasi, maka jumlah alkohol dan asam-asam organik yang berwujud cair dan yang dihasilkan akan semakin tinggi. Hal inilah yang menyebabkan tekstur tape yang dihasilkan semakin lunak seiring dengan lama fermentasi. 
Tabel 1. Hasil Uji Organoleptik Tape Pisang Kepok

\begin{tabular}{ccccc}
$\begin{array}{c}\text { Tape Pisang Kepok } \\
\text { Variasi Waktu } \\
\text { Fermentasi (hari) }\end{array}$ & Rasa & Warna & Tekstur & Aroma \\
\cline { 2 - 5 } & $1,84^{\mathrm{a}}$ & $2,10^{\mathrm{a}}$ & $2,30^{\mathrm{a}}$ & $1.78^{\mathrm{a}}$ \\
2 & $2,92^{\mathrm{b}}$ & $3,21^{\mathrm{b}}$ & $2,82^{\mathrm{b}}$ & $3.78^{\mathrm{c}}$ \\
3 & $5,34^{\mathrm{c}}$ & $4,43^{\mathrm{c}}$ & $5,56^{\mathrm{e}}$ & $5.26^{\mathrm{d}}$ \\
4 & $5,00^{\mathrm{c}}$ & $4,47^{\mathrm{c}}$ & $5,10^{\mathrm{d}}$ & $5.22^{\mathrm{d}}$ \\
5 & $2,62^{\mathrm{b}}$ & $4,55^{\mathrm{d}}$ & $3,60^{\mathrm{c}}$ & $2.52^{\mathrm{b}}$ \\
6 & $1,90^{\mathrm{a}}$ & $4,50^{\mathrm{d}}$ & $3,16^{\mathrm{b}}$ & $1.80^{\mathrm{a}}$ \\
\hline
\end{tabular}

\section{KESIMPULAN DAN SARAN}

\section{Kesimpulan}

Waktu Fermentasi berpengaruh terhadap nilai $\mathrm{pH}$, kadar gula, kadar alkohol dan organoleptik tape pisang kepok. Kriteria tape pisang kepok terbaik dihasilkan pada perlakuan waktu fermentasi selama 3 hari dengan nilai $\mathrm{pH} 4,76$; kadar gula $11,97 \%$ dan kadar alkohol 4,45\%. Nilai organoleptik tape pisang waktu fermentasi 3 hari untuk rasa, warna, tekstur dan aroma berturut-turut sebesar 5,34; 5,56 ; 4,43; dan 5,26 (4= sedikit suka, $5=$ suka). Berdasarkan hasil uji karakteristik kimia dan organoleptiknya tape pisang dengan waktu fermentasi 3- 4 hari layak untuk dikonsumsi.

\section{Saran}

1. Perlu dilakukan uji kadar gula pada pisang kepok setelah pengukusan sebagai kontrol fermentasi.

2. Perlu dikaji variasi pemberian ragi tape untuk menentukan dosis ragi yang tepat.

\section{DAFTAR PUSTAKA}

[BSN] Badan Standar Nasional. (1996). SNI No. 01-4018-1996: Batas Maksimum Alkohol dalam Makanan dan Minuman. Jakarta:BSN.

Alvarenga, R.M., Carrara, A.G., Silva, C., Oliveira, E.S., (2011). Potential Application of Saccharomyces Cerevisiae Strains for the Fermentation of Banana Pulp. Afr. J. Biotechnol. 10 (18):3608-3615.
Aurore, G., Parfait, B., \& Fahrasmane, L. (2009). Bananas, Raw Materials For Making Processed Food Products. Food Science and Technology. 20:7891.

Barus T, Wijaya LN. (2011). Mikrobiota Dominan Dan Perannya Dalam Cita Rasa "Tape" Singkong. Biota. 16:354361.

Bede, E.N., Okeke, C.E., Amandikwa, C., (2015). Physicochemical properties and sensory evaluation of Kunu-zaki beverage produced by substitution of sweet potato with fruits. Food Technol. 9 (3): 81-84.

Byarugaba-Bazirake, G.W., Byarugaba, W., Tumusiime, M., Kimono, D.A. (2014). The technology of producing banana wine vinegar from starch of banana peels. African Journal of Food Science and Technology. Vol. 5(1):1-5.

Dwidjoseputro. (2005). Dasar-Dasar Mikrobiologi. Jakarta: Djambatan.

Farnworth, E.R. (2003). Handbook of Fermented Functional Foods. Ed ke-2. Florida: CRC Pr.

Gebregergs, A., Gebresemati M., Sahu, O., (2016). Industrial Ethanol from Banana Peels for Developing Countries: Response Surface Methodology. Pacific Science Review A: Natural Science and Engineering 18: 22-29. 
Hasanah, H., Jannah, A., Fasya, A.G. (2012). Pengaruh Lama Fermentasi Terhadap Kadar Alkohol Tape Singkong (Manihot utilissima Pohl). ALCHEMY, Vol. 2 (1): 68-79.

Hidayat dan Suhartini. (2009). Mikrobiologi Industri. Andi. Yogyakarta.

Irianto, K, (2006), Mikrobiologi: Menguak Dunia Mikroorganisme Jilid 2, Bandung: CV. Yrama Widya: 214215.

Paulinea M., Alexandre O., Andoseh, B.K. (2017). Production Technique and Sensory Evaluation of Traditional Alcoholic Beverage Based Maize and Banana. International Journal of Gastronomy and Food Science. 10:1115.

Santosa, A. Prakosa, C. (2010). Karakteristik tape buah sukun hasil fermentasi Penggunaan konsentrasi ragi yang berbeda. Magistra, No. 73 Th. XXII: 48-55.

Shiga, T. M., Carpita N.C., Lajolo, F.M., Cordenunsi-Lysenko, B.R. (2017). Two Banana Cultivars Differ in Composition of Potentially Immunomodulatory Mannan and Arabinogalactan. Carbohydrate Polymers. 164 :31-41.

Sugiyono. (2010). Metode Penelitian Kuantitatif dan Kualitatif. $\mathrm{R} \& \mathrm{~B}$. Bandung: Alfabeta.

Suryaningsih, N.L.S., Pasaribu, Y.P. (2015). Dewaka Banana as an Alternative Energy Source. Procedia Food Science 3:211 - 215.

Umam, M. F. (2012). Kajian Karakteristik Minuman Sinbiotik Pisang Kepok (Musa paradisiaca forma typical) Dengan Menggunakan Starter Lactobacillus Acidophillus Ifo 13951 Dan Bifidobacterium Longum Atcc 15707. Jurnal Teknosains Pangan. Vol.1(1): 2-11.
Unika, A. Astuti, N. (2015). Pengaruh jumlah ragi dan waktu fermentasi terhadap sifat organoleptik Tapai pisang tanduk. e-journal Boga. Vol. 4(1): 192-201.

Yulianti, H.C. (2014). Uji Beda Kadar Alkohol Pada Tape Beras, Ketan Hitam Dan Singkong. Jurnal Teknika. Vol 6 (1):531-536. 